\title{
High dissociatives, nature versus nurture?
}

\author{
María José Pérez-Fabello ${ }^{1}$ (1) $\cdot$ Alfredo Campos ${ }^{2}$ (1)
}

Accepted: 21 December 2021

(c) The Author(s) 2022

\begin{abstract}
Non-pathological dissociative experiences are common among the general population, and anyone may experience them to some degree. Thus, the aim of this study was to assess the degree of dissociative experiences such as fantasy proneness, imagination, and absorption in fine arts undergraduates prior to beginning their artistic studies, and at the end of their studies at the faculty of fine arts. Moreover, education undergraduates were used as a comparison group. The sample consisted of 440 undergraduates (204 fine arts, and 236 education undergraduates; 224 first-year undergraduates, and 216 fourth-year undergraduates), who were administered three dissociative experiences tests: Dissociative Ability Scale, Dissociative Experiences Scale, and Questionnaire of Experiences of Dissociation. The working hypotheses were substantiated with dissociative experiences being a distinctive personality trait of fine arts undergraduates. We have found a grade level difference between first-year and fourth-year fine arts undergraduates, although the study does not examine the nature of the change itself. The results are discussed in the light of previous studies, and new lines of research proposed.
\end{abstract}

Keywords Dissociative experiences $\cdot$ Normative dissociation $\cdot$ Imagination $\cdot$ Fantasy proneness $\cdot$ Absorption $\cdot$ Fine arts students

\section{Introduction}

Though most dissociative processes are associated to clinical disorders, dissociative experiences occur in the general population, and non-pathological types of dissociation have been described, which are referred to as normative dissociation (Butler, 2006; Orbach, 1994; Spiegel \& Cardeña, 1991), or subclinical dissociation, in individuals with a high tendency to dissociate (Kihlstrom, 2005). Currently, nonpathological dissociative experiences are considered to be fairly frequent among the normal population (Krüger, 2020; Putnam, 1991; Romero-López, 2016; Ross et al., 1990; Spiegel \& Cardeña, 1991), and dissociation is viewed as

María José Pérez-Fabello

fabello@uvigo.es

Alfredo Campos

alfredo.campos@usc.es

1 Faculty of Fine Arts, Departament of Psychology, Universidade de Vigo, Maestranza 2, 36002 Pontevedra, Spain

2 Faculty of Psychology, Departament Psychology, University of Santiago de Compostela, Campus Vida, Xosé María Suárez Núñez, s/n, A Coruña 15782 Santiago de Compostela, Spain a psychological mechanism that is present to some degree in everybody (Bernstein \& Putnam, 1986), with new tests being designed to measure dissociation in healthy and pathological individuals (Černis et al., 2020, 2021; Marsden et al., 2021).

The frequency of dissociative experiences in the normal population is conceived in terms of intrinsic idiosyncratic personality traits (Kihlstrom, 2005). This would suggest that dissociation is not a pathological process in itself, and the tendency to dissociate may be linked to personality variables. Indeed, it has been suggested that the tendency to dissociate may be a cognitive factor reflecting individual differences in processing styles (Kwapil et al., 2002; Pope $\&$ Kwapil, 2000). Thus, several authors have examined the relation between the tendency to dissociate and known personality factors.

Putnam (1997) has proposed a behavioural model to explain the gradual development of emotions in children. In this model, children gradually develop the ability to freely move from emotional to behavioural states (from a state of crying to a state of calm), a process that is facilitated by metacognitive abilities. When children develop the ability to transition between states, they appear to become less dissociative. Thus, non-pathological dissociation could be 
linked to mind theory, inhibitory control, and other metacognitive abilities that are of particular interest for research in developmental psychology (see, Sodian \& Frith, 2008). An alternative line of research has linked non-pathological dissociation to fantasy proneness and imagination. What may be considered a sign of pathological dissociation in children, may be often considered a sign of creativity in adults. Imaginary friends are a classical example, and in specific circumstances actors may benefit from a healthy dose of non-pathological dissociation.

Strong correlations have been found between dissociative tendencies and factors of neuroticism, and openness to experiences (Kwapil et al., 2002; Ruiz et al., 1999). Moreover, dissociation in the normal population has been related to the tendency to schizotypy, or to experience psychotic phenomena such as distorted perceptions, and magical thinking (Pope \& Kwapil, 2000), which are closely connected to fantasy proneness. In fact, one of the most consistent findings observed in several studies was the relation between dissociation and fantasy proneness (Levin \& Spei, 2004; Lynn \& Rhue, 1988; Merckelbach \& Giesbrecht, 2006; Willson \& Barber, 1983). Numerous studies have found that high levels of dissociation were associated to high levels of daydreaming and fantasy proneness (Merckelbach \& Jelicic, 2004; Merckelbach et al., 2000; Waldo \& Merritt, 2000).

Furthermore, dissociative experiences have been associated to creativity given that creative inspiration is understood to occur in an altered state of mind (see Martindale, 1989). Sapp and Hitchock (2003) found a significant correlation between creative imagination and dissociative experiences. Likewise, Wolfradt and Pretz (2001) found depersonalization and unusual perceptive experiences could be intrinsically associated to creativity. Pérez-Fabello and Campos (2011a) observed fine arts undergraduates scoring high in dissociation also scored high in creative imagination and creative experiences as compared to undergraduates scoring low in dissociation, and the differences were significant. Similarly, when creativity was evaluated in terms of artistic production, fine arts undergraduates scoring high in dissociative experiences obtained better results in the artistic production factors evaluated (Pérez-Fabello \& Campos, 2011b). This underscores the higher tendency of creative individuals to have dissociative experiences, with several studies observing a higher frequency of dissociative experiences among fine arts undergraduates, in particular in items related to absorption, fantasy proneness, and imagination, than in psychology undergraduates (Pérez-Fabello \& Campos, 2011c), or social education undergraduates (Pérez-Fabello \& Campos, 2009).

It should be noted that the empirical data available suggests the tendency to dissociate in the general population is a factor depending on a person's character, described by a number of authors as an innate predisposition (Braun \& Sachs, 1985), or a biological capacity (Kluft, 1984,
1996). Several studies have measured empirically the relative weight of biological and environmental impact on the tendency to experience dissociative states (Becker-Blease et al., 2004; Braun \& Sachs, 1985; Jang et al., 1998; Kluft, 1984, 1996; Waller \& Ross, 1997). Waller and Ross (1997) analysed a voluntary sample of adolescent twins and found $45 \%$ of the variance was explained by environmental factors (that is, the environmental impact generating a similarity in dissociation among brothers), and 55\% was explained by nonshared environmental factors (that is, the environmental impact generating differences in dissociation among siblings). However, Jang et al. (1998) in a sample of adult monozygotic and dizygotic twins found 55\% of the intersubject variance (of the scores obtained on the dissociative experiences scale) was due to genetic or non-environmental factors. Similar results were obtained with children and adolescents, and in a third group of adopted sibling (BeckerBlease et al., 2004). It should be noted that this type of study has certain limitations in assuming that two people raised in the same family (blood brothers or adopted siblings) have inevitably been exposed to the same environmental conditions. Moreover, the reliability of questionnaires has been contested by the frequent lack of agreement in the descriptions of the same children by teachers and parents (BeckerBlease et al., 2004). Nevertheless, the results of these studies have corroborated the existence of a genetic component in the tendency to dissociative in the general population.

Bearing in mind that fine arts undergraduates present more dissociative experiences than other types of undergraduates, the aim of the represent study was to address the nature versus nurture issue involving high dissociative experiences, that is, were fine arts undergraduates high in dissociative experiences prior to beginning their undergraduate studies, or did their studies heighten dissociative experiences? Thus, two hypotheses were conjectured: the first contended that dissociative experiences would be high in fine arts undergraduates prior to beginning their undergraduate studies, and the second hypothesis was that dissociative experiences would increase in undergraduates by the end of their studies owing to the creative environment. The independent variable for the first hypothesis was the type of undergraduate studies, and the duration of undergraduate studies for the second hypothesis. The dependent variables were the scores on the scales of dissociative experiences.

\section{Methods and Materials}

\section{Participants}

The sample consisted of 440 undergraduates (204 fine arts undergraduates, and 236 education undergraduates); 335 women and 105 men, mean age 21.77 years, $(S D=4.78)$, 
range 17 to 25 years. A total of 224 were first-year undergraduates, and 216 fourth-year undergraduates. The education undergraduates were specialising in preschool and primary education and attended classes at the same university campus as fine arts undergraduates. All students freely volunteered to participate in the study.

\section{Materials}

The Spanish version (Pérez-Fabello \& Campos, 2017a) of the Dissociative Ability Scale (DAS; Fisher et al., 2013) was used. Additionally, the Spanish version (Icarán et al., 1996) of the Dissociative Experiences Scale (DES; Bernstein \& Putnam, 1986), and the Spanish translation of the Questionnaire of Experiences of Dissociation (QED; Riley, 1988) were administered.

The Spanish version (Pérez-Fabello \& Campos, 2017a) of the DAS is a 17-item questionnaire on everyday experiences, but not under the influence of alcohol or other drugs. Responses were scored using a five-point Likert-type scale where 1 indicated: "I am unable to do this", and 5 "I am very capable of doing this". The test consisted of two scales measuring two constructs of dissociation: autopilot and autoscopy. An example of an item on the autopilot scale is: "I have the ability to be so absorbed in a television show or movie that I can become unaware of other events that are occurring around me.", and an example from the autoscopy scale is: "I can observe my behavior as if I am watching someone else." Fisher et al. (2013), in the original study an alpha of 0.88 was obtained for the autopilot scale, and an alpha of 0.86 for the autoscopy scale.

The Spanish version (Icarán et al., 1996) of the DES is a 28-item questionnaire on the frequency of dissociative experiences. The items include experiences of amnesia, loss of consciousness, depersonalization, derealization, absorption, and identity disorders. Each item was scored on a 0 to 100 scale. Participants were required to score the frequency of their dissociative experiences by ticking a point on a dotted line where 0 was equal to never ( $0 \%$ of the time) and 100 equalled always ( $100 \%$ of the time). The total scores were calculated by averaging the 28 -item scores. The internal consistency obtained by Icarán et al. (1996) was 0.91 .

The QED (Riley, 1988) has 26 true/false items. The items were drawn from the clinical literature describing dissociative experiences. For example, "I have never come to without knowing where I was or how I got there". A Cronbach alpha of 0.77 was obtained by Riley (1988).

\section{Procedure}

The DAS, DES and QED questionnaires were administered to participants in groups of approximately 24 undergraduates in their usual classrooms. The order of tests was counterbalanced. All students were assured their results would remain anonymous and confidential, and written informed consent was obtained from all participants. The study was conducted in accordance with ethical standards of the Declaration of Helsinki of 2013 and was approved by the ethics committee of our university.

\section{Data Analysis}

Statistical analysis was performed using the IBM SPSS Statistics, Version 25.0, statistical software (IBM Corporation, Armonk, NY, USA). The internal consistency of the tests was calculated by the Cronbach's alpha.

In order to assess the effects of the type of undergraduate studies (fine arts or education), and the duration of undergraduate studies (first-year or fourth-year) on dissociative experiences and the abilities of the university undergraduates, three ANOVAs were performed of 2 academic years (first-year and fourth-year) $\times 2$ type of undergraduate studies (fine arts and education), the dependent variable in each ANOVA was the DAS, DES, and QED score, respectively.

\section{Results}

\section{Internal consistency of the scales}

The Cronbach alpha was used to determine the reliability of the tests administered in this study. The DAS obtained a Cronbach alpha of 0.80 for the autopilot scale, 0.68 for the autoscopy scale, and 0.80 for the total scale. The Cronbach's Alpha was 0.91 for the DES, and 0.75 for the QED.

\section{Results of Analysis of Variance}

To determine significant differences in dissociative experiences between the type of undergraduate studies: fine arts or education degrees, and between the duration of studies: firstyear and fourth-year, three ANOVAs were performed with different measures of dissociation. First, the DAS was used as the dependent variable (means and standard deviations are shown in Table 1). The results showed significant differences between the dissociative experiences scores obtained by fine arts undergraduates and education undergraduates, $F(1,436)=33.68, p<0.001, \eta_{p}{ }^{2}=0.07$, power $=1$. Fine arts undergraduates obtained higher scores than education undergraduates. The variable duration of studies was also significant, $F(1,436)=7.86, p=0.005, \eta_{p}{ }^{2}=0.02$, power $=0.80$. Fourth-year undergraduates scored higher on the scale than first-year undergraduates.

The interaction between the type of undergraduate studies and the duration of study was significant, $F(1$, $436)=8.56, p=0.004, \eta_{p}{ }^{2}=0.02$, power $=0.83$ (see 
Table 1 Means and Standard Deviations of the DAS according to the type of studies and the duration of studies

\begin{tabular}{|c|c|c|c|c|c|c|}
\hline \multirow{3}{*}{ DEGREE } & \multicolumn{6}{|c|}{ YEAR } \\
\hline & \multicolumn{2}{|c|}{ First-year } & \multicolumn{2}{|c|}{ Fourth-year } & \multicolumn{2}{|l|}{ Total } \\
\hline & $M$ & $S D$ & $M$ & $S D$ & $M$ & $S D$ \\
\hline Fine arts & 42.44 & 8.72 & 47.78 & 11.34 & 45.03 & 10.40 \\
\hline Education & 39.76 & 8.49 & 39.64 & 10.35 & 39.70 & 9.44 \\
\hline Total & 41.01 & 8.68 & 43.37 & 11.53 & 42.17 & 10.23 \\
\hline
\end{tabular}

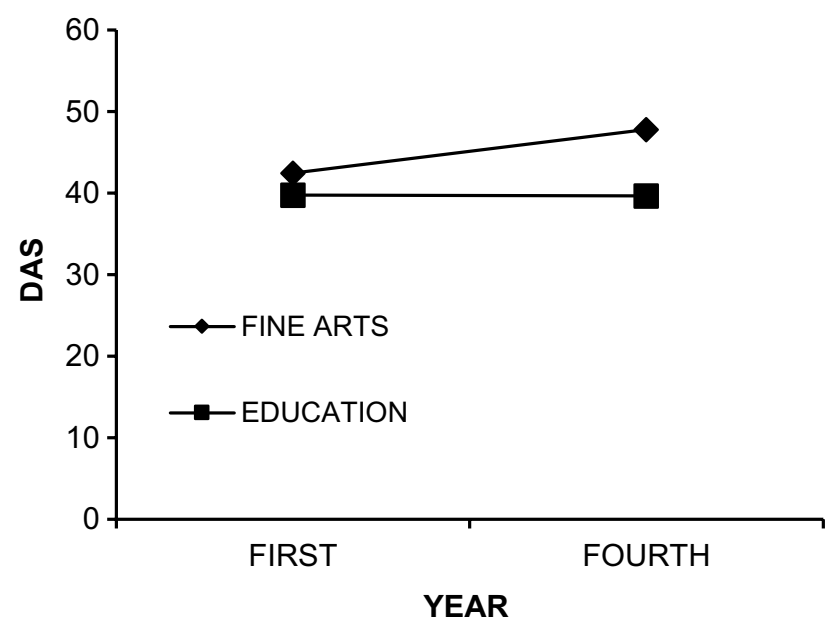

Fig. 1 Interaction between the type of studies and the duration of studies on the DAS scores

Fig. 1). First-year and fourth-year fine arts undergraduates showed significant differences in dissociative experiences (DAS), $t(202)=3.78, p<0.001$, with fourth-year undergraduates obtaining the highest scores. In comparison no significant differences, $t(234)=0.09, p=0.93$, were found between first-year and fourth-year education undergraduates. The comparison between first-year fine arts and first-year education undergraduates showed significant differences, $t(222)=2.33, p=0.02$. First-year fine arts undergraduates scored higher in dissociative experiences than first-year education undergraduates. Similar results were obtained between fourth-year fine arts, and fourth-year education undergraduates, $t(214)=5.51$, $p=0.02$. Fourth-year fine arts undergraduates experienced more dissociative experiences than fourth-year education undergraduates.

When the DES was used as the dependent variable (means and standard deviations of the DES are shown in Table 2), significant differences in dissociative experiences were observed between both types of undergraduate studies, $F(1,436)=38.15, p<0.001, \eta_{p}{ }^{2}=0.08$, power $=1$. Fine arts undergraduates obtained higher scores than education undergraduates. In contrast, the duration of studies was not a significant variable, $F(1,436)=3.58, p<0.06$, $\eta_{p}{ }^{2}=0.01$, power $=0.47$, but the interaction between the type of studies and the duration of studies was significant, $F(1$, 436) $=10.54, p<0.001, \eta_{p}{ }^{2}=0.02$, power $=0.90$.

Both first and fourth-year fine arts undergraduates exhibited significant differences in dissociative experiences, $t(202)=3.19, p=0.002$, with fourth-year undergraduates obtaining the highest scores. In contrast, no significant differences, $t(234)=1.10, p=0.27$ were found between firstyear and fourth-year education undergraduates. The comparison of both first-year degree courses showed significant differences, $t(222)=2.40, p<0.05$. First-year fine arts undergraduates scored higher in dissociative experiences than first-year education undergraduates. Significant differences were also found between fourth-year fine arts and fourthyear education undergraduates, $t(214)=5.913, p<0.001$. Fourth-year fine arts undergraduates scored higher in dissociative experiences than fourth-year education undergraduates (see Fig. 2).

Finally, the QED was used as the dependent variable (means and standard deviations of the QED are shown in Table 3). The results revealed significant differences in dissociative experiences between both types of university studies, $F(1,436)=115.28, p<0.001, \eta_{p}{ }^{2}=0.21$,
Table 2 Means and Standard Deviations of the DES, according to the type of studies and the duration of studies

\begin{tabular}{|c|c|c|c|c|c|c|}
\hline \multirow{3}{*}{ DEGREE } & \multicolumn{6}{|l|}{ YEAR } \\
\hline & \multicolumn{2}{|c|}{ First-year } & \multicolumn{2}{|c|}{ Fourth-year } & \multicolumn{2}{|l|}{ Total } \\
\hline & $M$ & $S D$ & $M$ & $S D$ & $M$ & $S D$ \\
\hline Fine arts & 18.43 & 10.73 & 24.18 & 14.77 & 21.22 & 13.14 \\
\hline Education & 15.15 & 9.75 & 13.63 & 11.40 & 14.40 & 10.61 \\
\hline Total & 16.69 & 10.33 & 18.47 & 14.05 & 17.56 & 12.31 \\
\hline
\end{tabular}




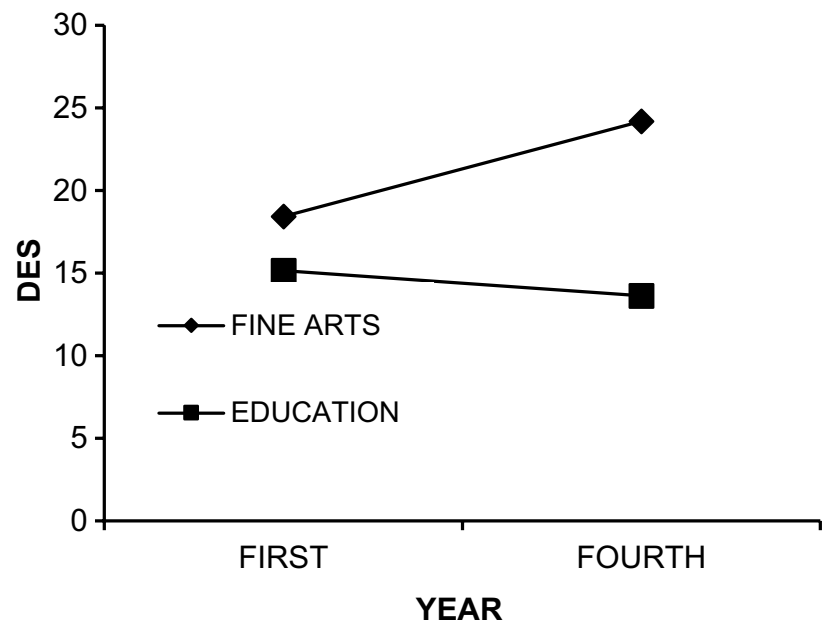

Fig. 2 Interaction between the type of studies and the duration of studies on the DES scores

power $=1$. Fine arts undergraduates scored higher on the QED than education undergraduates. However, the duration of studies was not a significant variable, $F(1$, 436) $=38.94, p=0.091, \eta_{p}{ }^{2}=0.007$, power $=0.39$, but there was a significant interaction between type of studies and the duration of studies, $F(1,436)=14.59, p<0.001$, $\eta_{p}{ }^{2}=0.03$, power $=0.97$.

Significant differences were found in dissociative experiences between first-year and fourth-year fine arts undergraduates, $t(202)=3.45, p=0.001$, with fourth-year undergraduates obtaining higher scores. In comparison, no significant differences, $t(234)=1.71, p=0.09$, were found between first-year and fourth-year education undergraduates. However, significant differences, $t(222)=5.05$, $p<0.001$, were observed between first-year undergraduates, with first-year fine arts undergraduates scoring higher in dissociative experiences than first-year education undergraduates. Moreover, significant differences, $t(214)=9.97$, $p<0.001$, were found between fourth-year fine arts undergraduates, and fourth-year education undergraduates, with fourth-year fine arts undergraduates obtaining higher scores in dissociative experiences than fourth-year education undergraduates (See Fig. 3).

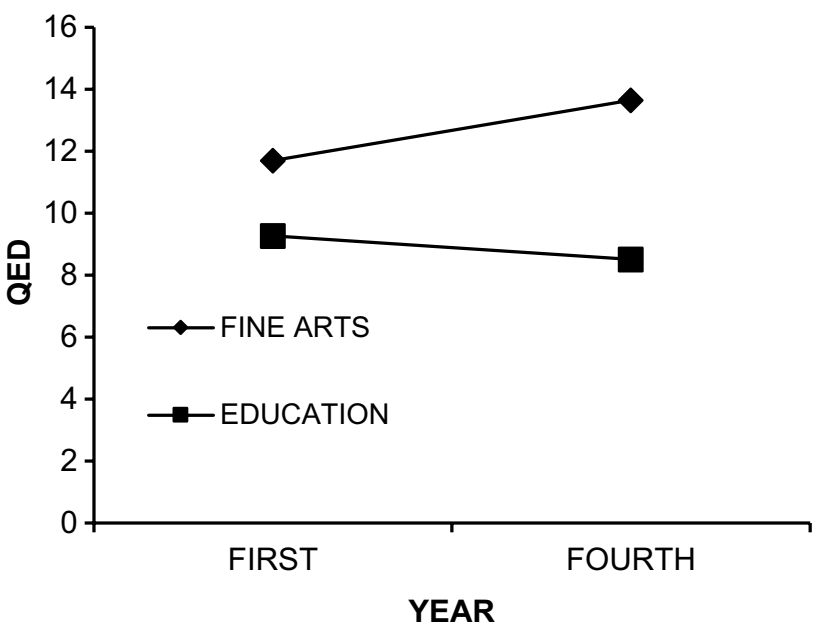

Fig. 3 Interaction between the type of studies and the duration of studies on the QED scores

\section{Discussion}

The Cronbach's alphas obtained in the tests administered in this study were similar to those reported in previous studies. Though on the DAS, Fisher et al. (2013) obtained slightly higher alphas of 0.88 for the autopilot scale, and 0.86 for the autoscopy scale, Pérez -Fabello and Campos (2017a) in the Spanish version of the DAS obtained results similar to the present study. The Cronbach's alpha for the autopilot scale was 0.76 , and 0.69 for the autoscopy scale, and the alpha for the total scale was 0.82. The Cronbach's alpha of the DES coincided with alphas found in other studies: 0.90 and 0.91 (Ensink \& Van Otterloo, 1989); 0.91 (Icarán et al., 1996; Pérez-Fabello \& Campos, 2017a); 0.90 (Pérez-Fabello \& Campos, 2011a); 0.88 (Pérez-Fabello \& Campos, 2011b); and 0.92 (Pérez-Fabello \& Campos, 2017b). Finally, the Cronbach's alpha of the QED was close to that obtained in previous studies: 0.77 (Pérez-Fabello \& Campos, 2011a; Riley, 1988), and 0.75 (Pérez-Fabello \& Campos, 2017b).

The results of the ANOVAs corroborated the first hypothesis as fine arts undergraduates experienced more dissociative experiences than education undergraduates. These differences between both types of undergraduate studies
Table 3 Means and Standard Deviations of the QED, according to the type of studies and the duration of studies

\begin{tabular}{|c|c|c|c|c|c|c|}
\hline \multirow{3}{*}{ DEGREE } & \multicolumn{6}{|l|}{ YEAR } \\
\hline & \multicolumn{2}{|c|}{ First-year } & \multicolumn{2}{|c|}{ Fourth-year } & \multicolumn{2}{|l|}{ Total } \\
\hline & $M$ & $S D$ & $M$ & $S D$ & $M$ & $S D$ \\
\hline Fine arts & 11.70 & 3.75 & 13.64 & 4.28 & 12.64 & 4.12 \\
\hline Education & 9.26 & 3.46 & 8.51 & 3.27 & 8.89 & 3.38 \\
\hline Total & 10.40 & 3.79 & 10.86 & 4.54 & 10.63 & 4.18 \\
\hline
\end{tabular}


were observed in first-year undergraduates, in fourth-year undergraduates, and in the undergraduate total. That fine arts undergraduates are characterized for having more dissociative experiences than undergraduates in other disciplines has been corroborated by previous studies (Pérez-Fabello \& Campos, 2009, 2011c). This finding underpins the approach of several authors (Kihlstrom, 2005; Kwapil et al., 2002; Pope \& Kwapil, 2000), who claim dissociative experiences in normal individuals are associated to personal idiosyncrasies, and are considered personality traits. Fine arts undergraduates were immersed in a creative environment, which accounted for the high scores in the dissociation tests linked to fantasy proneness, imagination, and absorption, attributes associated to creativity (Pérez-Fabello \& Campos, 2009; Pérez-Fabello \& Campos, 2011a, 2011b, 2011c).

The most significant findings of this study were to corroborate that the tendency to dissociate in fine arts undergraduates was due to the intrinsic characteristics of creative individuals, and as such, prexisted the beginning of formal instruction in fine arts; and that the tendency to dissociate increased throughout the degree in fine arts. In terms of the nature versus nurture dichotomy or genetics versus environment, the results of this study have substantiated the findings of numerous authors (Becker-Blease et al., 2004; Braun \& Sachs, 1985; Jang et al., 1998; Kluft, 1984, 1996; Waller \& Ross, 1997). Thus, the data showed significant differences in the dissociative experiences of fine arts undergraduates, with fourth-year undergraduates obtaining the highest scores. In contrast, no significant differences in dissociative experiences were found between first and fourth-year education undergraduates. This would suggest that studies in fine arts fostered the tendency to dissociate. Furthermore, the significant differences between the first-year fine arts undergraduates and first-year education undergraduates underscored that undergraduates enrolling in fine arts had a personality factor involving a tendency to dissociate, which was inherent to each individual. These results are in agreement with previous studies showing the tendency to dissociate was balanced between the impact of biological and environmental factors (Becker-Blease et al., 2004; Braun \& Sachs, 1985; Jang et al., 1998; Kluft, 1984, 1996; Waller \& Ross, 1997).

It is worth noting that the data in this study were confirmed with three of the most extensively used dissociation tests i.e., the most updated DAS that is used in the normal population, and the DES and the QED, used both in normal and pathological populations. The fact that similar results were obtained with the three tests lent further support to the working hypothesis of this study.

The main limitations of this study were that the comparison group was restricted to education undergraduates, and the existence of pathologies in the fine arts or in the education undergraduates was not evaluated. Further studies are required to assess dissociative experiences in other academic fields and to control the existence of pathologies. Moreover, bearing in mind the profile of first-year fine arts undergraduates entails the greater tendency to dissociate as compared to undergraduates in other disciplines, it would be interesting to determine when this differentiation becomes visible. Research is also required to examine the tendency to dissociate in secondary education students who begin to specialize in either arts, humanities, or sciences.

\section{Conclusión}

The results of this study underscored fine arts undergraduates have a tendency to dissociation as a personality trait as a personality trait. This characteristic trait is prior to beginning studies in fine arts and increases during studies at the faculty of fine arts. Therefore, dissociative experiences of fine arts undergraduates constitute part of their personality that are enhanced by a creative environment; so that, both genetic and environmental factors have an impact on the dissociative experiences of fine arts undergraduates.

Funding Open Access funding provided thanks to the CRUE-CSIC agreement with Springer Nature. Funding for open access charge: Universidade de Vigo/CISUG.

Data Availability The datasets generated during and/or analysed during the current study are available from the corresponding author on reasonable request.

\section{Declarations}

Conflict of interest On behalf of all authors, the corresponding author states that there is no conflict of interest.

Open Access This article is licensed under a Creative Commons Attribution 4.0 International License, which permits use, sharing, adaptation, distribution and reproduction in any medium or format, as long as you give appropriate credit to the original author(s) and the source, provide a link to the Creative Commons licence, and indicate if changes were made. The images or other third party material in this article are included in the article's Creative Commons licence, unless indicated otherwise in a credit line to the material. If material is not included in the article's Creative Commons licence and your intended use is not permitted by statutory regulation or exceeds the permitted use, you will need to obtain permission directly from the copyright holder. To view a copy of this licence, visit http://creativecommons.org/licenses/by/4.0/.

\section{References}

Becker-Blease, K. A., Deater-Deckard, K., Eley, T., Freyd, J. J., Stevenson, J., \& Plomin, R. (2004). A genetic analysis of individual differences in dissociative behaviors in childhood and adolescence. Journal of Child Psychology, 45(3), 522-532. https://doi.org/10. 1111/j.1469-7610.2004.00242.x 
Bernstein, E. M., \& Putnam, F. W. (1986). Development, reliability, and validity of a dissociation scale. Journal of Nervous and Mental Disease, 174(12), 727-735. https://doi.org/10.1097/00005 053-198612000-00004

Braun, B. G., \& Sachs, R. G. (1985). The development of multiple personality disorder: Predisposing, precipitating and perpetuating factors. In R. P. Kluft. (Ed.), Childhood antecedents of multiple personality disorder (pp. 37-64). American Psychiatric Press.

Butler, L. D. (2006). Normative dissociation. Psychiatric Clinics of North America, 29(1), 45-62. https://doi.org/10.1016/j.psc.2005. 10.004

Černis, E., Beierl, E., Molodynski, A., Ehlers, A., \& Freeman, D. (2021). A new perspective and assessment measure for common dissociative experiences: 'Felt sense of anomaly.' PLOS ONE, 16(2), e0247037. https://doi.org/10.1371/journal.pone.0247037

Černis, E., Bird, J. C., Molodynski, A., Ehlers, A., \& Freeman, D. (2020). Cognitive appraisals of dissociation in psychosis: A new brief measure. Behavioural and Cognitive Psychotherapy, 48(1), 1-13. https://doi.org/10.1017/S1352465820000958

Ensink, B. J., \& Van Otterloo, D. (1989). A validation study of the DES in the Netherlands. Dissociation, 2(4), 221-223.

Fisher, W., Johnson, A., \& Elkins, G. (2013). Principal component analysis of a measure of non-pathological dissociation: The Dissociative Ability Scale. Contemporary Hypnosis and Integrative Therapy, 30, 32-41.

Icarán, E., Colom, R., \& Orengo, F. (1996). Experiencias disociativas: Una escala de medida [Dissociative experiences: A scale of measure]. Anuario De Psicología, 70, 69-84.

Jang, K. L., Paris, J. M., Zweig-Frank, H., \& Livesley, W. J. (1998). Twin study of dissociative experience. The Journal of Nervous and Mental Disease, 186(6), 345-351. https://doi.org/10.1097/ 00005053-199806000-00004

Kihlstrom, J. (2005). Dissociative disorders. Annual Review of Clinical Psychology, 1, 227-253. https://doi.org/10.1146/annurev.clinp sy.1.102803.143925

Kluft, R. P. (1984). An introduction to multiple personality disorder. Psychiatric Annals, 14(1), 19-24. https://doi.org/10.3928/00485713-19840101-05

Kluft, R. P. (1996). Dissociative identity disorder. In L. K. Michelson \& W. J. Ray (Eds.), Handbook of dissociation: Theoretical, empirical, and clinical perspectives (pp. 337-366). Plenum Press.

Krüger, C. (2020). Culture, trauma, and dissociation: A broadening perspective for our field. Journal of Trauma \& Dissociation, 21(1), 1-13. https://doi.org/10.1080/15299732.2020.1675134

Kwapil, T. R., Wrobel, M. J., \& Pope, C. A. (2002). The five-factor personality structure of dissociative experiences. Personality and Individual Differences, 32(3), 431-443. https://doi.org/10.1016/ S0191-8869(01)00035-6

Levin, R., \& Spei, E. (2004). Relationship of purported measures of pathological and nonpathological dissociation to self-reported psychological distress and fantasy immersion. Assessment, 11(2), 160-168. https://doi.org/10.1177/1073191103256377

Lynn, S. J., \& Rhue, J. W. (1988). Fantasy proneness: Hypnosis, developmental antecedents, and psychopathology. American Psychologist, 43(1), 35-44. https://doi.org/10.1037/0003-066X.43.1.35

Martindale, C. (1989). Personality, situation, and creativity. In J. A. Glover, R. R. Ronning, \& C. R. Reynolds (Eds.), Handbook of creativity (pp. 211-232). Plenum Press.

Marsden, L., Longden, E., Parry, S., Morrison, A., \& Varese, F. (2021). Development and initial evaluation of a measure of positive beliefs about dissociative experiences. Journal of Trauma \& Dissociation, 22(3), 349-364. https://doi.org/10.1080/15299732. 2020.1869641

Merckelbach, H., \& Giesbrecht, T. (2006). Subclinical dissociation, schizotypy, and traumatic distress. Personality and Individual
Differences, 40(2), 365-374. https://doi.org/10.1016/j.paid.2005. 07.007

Merckelbach, H., \& Jelicic, M. (2004). Dissociative symptoms are related to endorsement of vague trauma items. Comprehensive Psychiatry, 45(1), 70-75. https://doi.org/10.1016/S0010440X(03)00149-4

Merckelbach, H., Muris, P., Rassin, E., \& Horselenberg, R. (2000). Dissociative experiences and interrogative suggestibility in college students. Personality and Individual Differences, 29(6), 11331140. https://doi.org/10.1016/S0191-8869(99)00260-3

Orbach, I. (1994). Dissociation, physical pain, and suicide: A Hypothesis. Suicide and Life-Threatening Behaviour, 24(1), 68-79. https:// doi.org/10.1111/j.1943-278X.1994.tb00664.X

Pérez-Fabello, M. J., \& Campos, A. (2009). ¿Son las expericencias disociativas una característica distintiva de los estudiantes de bellas artes? Un estudio preliminar [Are the dissociative experiences a distinguishing characteristic of students of fine arts? A preliminary study]. In B. D. Silva, L. S. Almeida, A. Barca, \& M. Peralbo (Eds.), Actas do X Congresso Internacional Galego-Português de Psicopedagogia (pp. 563-568). Universidade do Minho.

Pérez-Fabello, M. J., \& Campos, A. (2011a). Dissociative experiences and creativity in fine arts students. Creativity Research Journal, 23(1), 38-41. https://doi.org/10.1080/10400419.2011.545721

Pérez-Fabello, M. J., \& Campos, A. (2011b). Dissociative experiences, creative imagination, and artistic production in students of fine arts. Thinking Skills and Creativity, 6(1), 44-48. https://doi.org/ 10.1016/j.tsc.2010.11.001

Pérez-Fabello, M. J., \& Campos, A. (2011c). The dissociative experiences of fine arts students. Nordic Psychology, 63(1), 72-81. https://doi.org/10.1027/1901-2276/a000028

Pérez-Fabello, M. J., \& Campos, A. (2017a). Factor structure and reliability of the Spanish version of the Dissociative Ability Scale. Journal of Trauma \& Dissociation, 18(2), 223-232. https://doi org/10.1080/15299732.2016.1225625

Pérez-Fabello, M. J., \& Campos, A. (2017b). Dissociative experiences and vividness of auditory imagery. Creativity Research Journal, 29(2), 200-205. https://doi.org/10.1080/10400419.2017.1303310

Pope, C. A., \& Kwapil, T. R. (2000). Dissociative experiences in hypothetically psychosis-prone college students. Journal of Nervous and Mental Disease, 188(8), 530-536. https://doi.org/10.1097/ 00005053-200008000-00009

Putnam, F. W. (1991). Dissociative phenomena. In A. Tasman \& S. M. Goldfinger (Eds.), American psychiatric press review of psychiatry (pp. 145-160). American Psychiatric Press.

Putnam, F. W. (1997). Dissociation in children and adolescents. Guilford Press.

Riley, K. C. (1988). Measurement of dissociation. The Journal of Nervous and Mental Disease, 176(7), 449-450. https://doi.org/ 10.1097/00005053-198807000-00008

Romero-López, M. J. (2016). Una revisión de los trastornos disociativos: De la personalidad múltiple al estrés postraumático [A review of the dissociative disorders: From multiple personality disorder to the posttraumatic stress]. Anales De Psicología / Annals of Psychology, 32(2), 448-456. https://doi.org/10.6018/ analesps.32.2.21830

Ross, C. A., Joshi, S., \& Currie, R. (1990). Dissociative experiences in the general population. American Journal of Psychiatry, 147(11), 1547-1552. https://doi.org/10.1176/ajp.147.11.1547

Ruiz, M. A., Pincus, A. L., \& Ray, W. J. (1999). The relationship between dissociation and personality. Personality and Individual Differences, 27(2), 239-249. https://doi.org/10.1016/S01918869(98)00236-0

Sapp, M., \& Hitchock, K. (2003). Creative imagination, absorption, and dissociation with African American college students. Sleep and Hypnosis, 5(2), 95-104. Retrieved from https://search.proqu 
est.com/scholarly-journals/creative-imagination-absorption-disso ciation-with/docview/620107686/se-2?accountid=17261

Spiegel, D., \& Cardeña, E. (1991). Disintegrated Experience: The dissociative disorders revisited. Journal of Abnormal Psychology, 100(3), 366-378. https://doi.org/10.1037/0021-843X.100.3.366

Sodian, B., \& Frith, U. (2008). Metacognition, theory of mind, and self-control: The relevance of high-level cognitive processes in development, neuroscience, and education. Mind, Brain, and Education, 2(3), 111-113. https://doi.org/10.1111/j.1751-228X. 2008.00040.x

Waldo, T. G., \& Merritt, R. D. (2000). Fantasy proneness, dissociation, and DSM-IV axis II symptomatology. Journal of Abnormal Psychology, 109(3), 555-558. https://doi.org/10.1037/0021-843X. 109.3.555

Waller, N., \& Ross, C. A. (1997). The prevalence and biometric structure of pathological dissociation in the general population:
Taxometric and behavior genetic findings. Journal of Abnormal Psychology, 106(4), 499-510. https://doi.org/10.1037/0021-843X. 106.4.499

Willson, S. C., \& Barber, T. X. (1983). Fantasy-prone personality: Implications for understanding imagery, hypnosis, and parapsychological phenomena. In A. A. Sheikh (Ed.), Imagery: Current theory, research, and application (pp. 340-387). Wiley.

Wolfradt, W., \& Pretz, J. E. (2001). Individual differences in creativity: Personality, story writing, and hobbies. European Journal of Personality, 15(4), 297-310. https://doi.org/10.1002/per.409

Publisher's note Springer Nature remains neutral with regard to jurisdictional claims in published maps and institutional affiliations. 